\title{
Threonine Catabolism in Trypanosoma brucei
}

\author{
By D. J. LINSTEAD,* R. A. KLEIN AND G. A. M. CROSS \\ Medical Research Council Biochemical Parasitology Unit, Molteno Institute, \\ Downing Street, Cambridge CB2 $3 E E$
}

(Received 19 April 1977)

L-Threonine is catabolized by Trypanosoma brucei to give equimolar quantities of glycine and acetate. The pathway, which involves the two enzymes L-threonine dehydrogenase (EC I.I.I.103) and aminoacetone synthase (acetyl-CoA:glycine $C$-acetyltransferase, EC 2.3. I.29) and subsequent hydrolysis of the acetyl-CoA, is most active in cultured trypanosomes but is also present in bloodstream forms. L-Threonine dehydrogenase from both culture and bloodstream forms of trypanosomes has an apparent molecular weight of between 28000 and 38000 , and is sensitive to a wide range of sulphydryl reagents.

\section{INTRODUCTION}

Threonine catabolism can occur by a number of different routes (Gaitonde, 1975), in particular, deamination by L-threonine deaminase (EC 4.2.I.16) (Umbarger \& Brown, 1957), aldol cleavage by L-threonine aldolase (EC 2. I .2 . I) (Karasek \& Greenberg, 1957; Morris, I969), and oxidation by L-threonine dehydrogenase (EC I. I. I . I03) (Neuberger \& Tait, 1962). We have recently shown that extensive breakdown of L-threonine occurred during growth of the parasitic haemoflagellate Trypanosoma brucei in a defined medium. Breakdown of $L$-threonine resulted in the appearance of equimolar amounts of glycine and acetate by a pathway which was highly sensitive to the sulphydryl blocking reagent tetraethyl thiuram disulphide (Cross, Klein \& Linstead, 1975).

The formation of glycine and acetate would be compatible with the operation of L-threonine aldolase plus an aldehyde oxidase catalysing the reaction:

$$
\mathrm{CH}_{3} \mathrm{CH}(\mathrm{OH}) \mathrm{CH}\left(\mathrm{NH}_{2}\right) \mathrm{COOH} \longrightarrow \mathrm{NH}_{2} \mathrm{CH}_{2} \mathrm{COOH}+\mathrm{CH}_{3} \mathrm{CHO} \longrightarrow \mathrm{CH}_{3} \mathrm{COOH}
$$

Equally, however, it would be consistent with the combined operation of L-threonine dehydrogenase and aminoacetone synthase (acetyl-CoA:glycine $C$-acetyltransferase, EC 2.3. I.29) in an analogous manner to the inducible pathway found by McGilvray \& Morris (1969) in a species of Arthrobacter. In this case the pathway would be:

$$
\begin{aligned}
& \mathrm{CH}_{3} \mathrm{CH}(\mathrm{OH}) \mathrm{CH}\left(\mathrm{NH}_{2}\right) \mathrm{COOH}+\mathrm{NAD}^{+} \longrightarrow \mathrm{CH}_{3} \mathrm{COCH}\left(\mathrm{NH}_{2}\right) \mathrm{COOH}+\mathrm{NADH}+\mathrm{H}^{+} \\
& \longrightarrow \mathrm{NH}_{2} \mathrm{CH}_{2} \mathrm{COOH}+\mathrm{CH}_{3} \mathrm{COSCOA} \longrightarrow \mathrm{CH}_{3} \mathrm{COOH}
\end{aligned}
$$

This route for the catabolism of $\mathbf{L}$-threonine is fairly widespread among other microorganisms (Bell \& Turner, 1976).

Because of the possible importance of L-threonine in the nutrition of T. brucei, and the potential value of inhibitors of $L$-threonine utilization as trypanocides, we have attempted to differentiate between the two possibilities, and have shown that L-threonine catabolism in $T$. brucei occurs exclusively via the second pathway involving the dehydrogenase and transferase. Moreover, we have recently demonstrated that these protozoa utilize the acetylCoA generated from threonine as a preferred source of carbon for lipid synthesis in culture, even in the presence of large concentrations of glucose (Klein \& Linstead, 1976).

* Present address: Wellcome Research Laboratories, Langley Court, Beckenham, Kent BR3 3BS. 


\section{METHODS}

Trypanosomes. Bloodstream forms of Trypanosoma brucei strain 427 (monomorphic) and Trypanosoma brucei brucei $\mathbf{S 4 2}$ (pleiomorphic) were stored as stabilates in liquid nitrogen, and were passaged at 3 to 4 day intervals through male CFY rats (Anglia Laboratory Animals, Huntingdon) for use as required. Strain histories were as described by Cross \& Manning (1973). Parasitized blood was obtained by aortic puncture and trypanosomes were prepared by the column procedure of Lanham (1968), using a separation buffer containing (mM): $\mathrm{NaCl}, 40 \cdot 5 ; \mathrm{NaH}_{2} \mathrm{PO}_{4}, 2 \cdot 7 ; \mathrm{Na}_{2} \mathrm{HPO}_{4}, 5 \mathrm{I} \cdot 3$; and D-glucose $55 \cdot 6$; adjusted to $\mathrm{pH} 8 \cdot 0$ (Klein, Linstead \& Wheeler, 1975).

A culture form of $T . b$. brucei, strain s42, was grown in a defined medium at $25{ }^{\circ} \mathrm{C}$ (Cross \& Manning, 1973), modified as described previously (Klein et al., 1975). Cells were grown in batches of $20 \mathrm{ml}$ medium without shaking or aeration, other than by diffusion, in $150 \mathrm{ml}$ closed bottles. The individual cultures in a batch were combined during the late-exponential growth phase (approximately $10^{7}$ organisms $\mathrm{ml}^{-1} ; 3$ to 4 days after inoculation), and the trypanosomes were harvested by centrifuging at $4000 \mathrm{~g}_{\mathrm{av}}$ for $10 \mathrm{~min}$ at $4{ }^{\circ} \mathrm{C}$. The cell pellet was resuspended in $20 \mathrm{ml}$ ice-cold buffer and recentrifuged, this procedure being repeated three times; the pellet was finally resuspended in buffer and kept on ice until required.

Crithidia fasciculata. The Anopheline isolate of $C$. fasciculata was maintained at $25{ }^{\circ} \mathrm{C}$ in the defined medium described by Kidder \& Dutta (1958). Cells were harvested and washed as detailed above for trypanosomes.

Chemicals. Acetyl-CoA, NAD ${ }^{+}, \mathrm{NADP}^{+}$, tetraethyl thiuram disulphide (TETD), 5,5'-dithiobis(2-nitrobenzoic acid), D-threonine and reduced glutathione (GSH) were obtained from Sigma. TETD was recrystallized from ethanol/chloroform before use. Tetramethyl thiuram disulphide and aminoacetone were synthesized and purified as described below. Chromatographically homogeneous L-threonine and DL-threonine (allo-free) were obtained from BDH and L-[U-14 C]threonine $\left(232 \mathrm{mCi} \mathrm{mmol}^{-1}\right)$ was from The Radiochemical Centre, Amersham. All other reagents were of analytical grade.

I-Aminopropan-2-one (aminoacetone) hydrochloride and the semicarbazone hydrochloride were prepared from glycine using the procedure described by Hepworth (1973). The identity of the synthetic material was confirmed by n.m.r. spectroscopy and melting point data.

Radioactive aminoacetone, produced metabolically, was identified by recrystallization of the semicarbazone to constant specific activity in the presence of a large excess of unlabelled aminoacetone hydrochloride as carrier. The procedure used for preparing the derivative on a small scale is described by Vogel (1959). The original quantity of radioactivity, present as aminoacetone, could be inferred from the asymptotic value of the specific activity for the semicarbazone. The identity and purity of the semicarbazone after the final recrystallization was confirmed by its n.m.r. spectrum and melting point. Radioactive aminoacetone, produced in cell extracts, was separated on a Locarte automatic amino-acid analyser equipped with a flowtype scintillation counter. Under the buffer conditions used, synthetic aminoacetone gave a sharp symmetric peak at the leading edge of the ammonia peak.

Tetramethyl thiuram disulphide, and the diethyl and dimethyl thiocarbamic acids were prepared from the appropriate secondary amine and carbon disulphide using iodine as the oxidizing agent (Cummings \& Simmons, 1928). The identity of the products was confirmed by n.m.r. spectroscopy, melting points, and elemental analysis.

Preparation of assay mixtures. Extracts of both bloodstream (s42 and 427) and culture forms of T. brucei, suitable for enzyme assay, were prepared by adding 0.01 to $0.1 \%(w / v)$ Triton $X-100$ (scintillation grade, Koch-Light) to a cell suspension in buffer at $4{ }^{\circ} \mathrm{C}$ (approx. $5 \times 10^{8}$ organisms $\mathrm{ml}^{-1}$ in $100 \mathrm{~mm}-\mathrm{Tris} / \mathrm{HCl}$, pH 7.9). More than $99 \%$ of the trypanosomes were lysed by this procedure, as judged by phase contrast microscopy.

Alternatively, homogenates ( $>95 \%$ broken cells) were prepared by sonicating a suspension of trypanosomes ( 2 to $5 \mathrm{ml}$, approx. $5 \times 10^{8}$ organisms $\mathrm{ml}^{-1}$ ) in sucrose buffer $(0.25 \mathrm{M}$-sucrose in $0.02 \mathrm{M}$-Tris/ $\mathrm{HCl}$ pH 7.9) using a Dawe Soniprobe type I I $30 \mathrm{~A}$ (Io s, 4 A, $4{ }^{\circ} \mathrm{C}$; Dawe Instruments, London). Homogenates of $C$. fasciculata were also prepared using these methods.

For the separation of the particulate and soluble fractions, the homogenate was diluted with sucrose buffer and centrifuged $\left(30000 \mathrm{gav}_{\mathrm{av}}, 30 \mathrm{~min}, 4^{\circ} \mathrm{C}\right.$ ). The particulate fraction was washed twice by centrifugation and finally suspended in approximately $\mathrm{I} \mathrm{ml}$ sucrose buffer. Homogenates could be stored at $-20^{\circ} \mathrm{C}$ with a loss in threonine dehydrogenase activity of less than $10 \%$ per month; however, it was advantageous to include $\mathrm{I}$ mM-dithiothreitol if the sample was to be stored for more than a week. Preparations containing dithiothreitol could not be used in studies involving the sulphydryl inhibitors.

Whole cells were incubated at $25^{\circ} \mathrm{C}\left(2 \mathrm{ml}, 3 \times 10^{8}\right.$ organisms $\left.\mathrm{ml}^{-1}\right)$ in medium at pH 7.4 containing (mM): $\mathrm{KCl}, 5 ; \mathrm{NaCl}, 80 ; \mathrm{MgSO}_{4}, \mathrm{I} ; \mathrm{Na}_{2} \mathrm{HPO}_{4}, 20 ; \mathrm{NaH}_{2} \mathrm{PO}_{4}, 2 ; \mathrm{D}$-glucose, $5 ;$ L-threonine, O.I; and L-[U-14 C] threonine at $\mathrm{I} \mu \mathrm{Ci} \mathrm{ml}^{-1}$. Cell homogenates or lysates were incubated in $82.5 \mathrm{~mm}$-sodium phosphate buffer 
pH 7.6, containing $100 \mu \mathrm{M}-\mathrm{L}-$-threonine together with added $\mathrm{L}-\left[\mathrm{U}-{ }^{14} \mathrm{C}\right]$ threonine. The following compounds were added where appropriate (mM): pyridoxal 5-phosphate, I; thiamin pyrophosphate, I; coenzyme A, 0.5; sodium fluoride, 50 (to suppress glycolysis); $\mathrm{NAD}^{+}$or $\mathrm{NADP}^{+}, \mathrm{I}$. Incubation mixtures were deproteinized by treatment with trichloroacetic acid $(5 \%, w / v)$ on ice, followed by centrifugation $\left(1000 \mathrm{~g}_{\mathrm{av}}, 15 \mathrm{~min}\right)$ to remove protein. Excess trichloroacetic acid was removed by ether extraction.

L-Threonine dehydrogenase (L-threonine: $\mathrm{NAD}^{+}$oxidoreductase, EC I I I I . 103). This was assayed according to the method of McGilvray \& Morris (1971 a) by following the reduction of $\mathrm{NAD}^{+}$at $340 \mathrm{~nm}$ $\left(\epsilon=6.22 \times 10^{3} 1 \mathrm{~mol}^{-1} \mathrm{~cm}^{-1}\right)$. The assay mixture contained $(\mathrm{mM}): \mathrm{NAD}^{+}, 0.5$; Tris/HCl $\mathrm{pH} 8.5,200$; L-threonine, 30; enzyme preparation, 10 to $100 \mu \mathrm{l}$; final volume, $\mathrm{I} \mathrm{ml}$; light path, $\mathrm{I} \mathrm{cm}$. Specific activities were calculated as $\mathrm{nmol} \mathrm{NAD}^{+}$reduced $\mathrm{min}^{-1}(\mathrm{mg} \text { protein })^{-1}$. The concentrations of $\mathrm{L}$-threonine and $\mathrm{NAD}^{+}$ used were at least twice the apparent $K_{m}$ values for these substrates. Contaminating activity due to nonspecific NADH oxidase in the extracts was $<1$ to $2 \%$ of the threonine dehydrogenase activity.

Aminoacetone synthase (acetyl-CoA:glycine $C$-acetyltransferase, EC 2.3.1.29). This was assayed at room temperature by the method of McGilvray \& Morris (I97I $b$ ). The reaction sequence is:

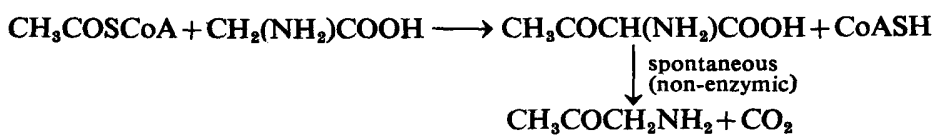

The production of $\mathrm{CoA}$, as a result of the reaction between glycine and acetyl-CoA, was followed using 5,5'-dithiobis(2-nitrobenzoic acid) (Ellman, 1959) at $412 \mathrm{~nm}\left[\epsilon=\mathrm{I} \cdot 36 \times 10^{4} \mathrm{I} \mathrm{mol}^{-1} \mathrm{~cm}^{-1}\right.$ for the thiophenate anion (McGilvray \& Morris, 1969)]. The assay mixture contained (mM): $\mathrm{K}_{2} \mathrm{HPO}_{4} \mathrm{pH} 7 \cdot 5,200 ;$ acetyl-CoA, $0.5 ; 5,5^{\prime}$-dithiobis(2-nitrobenzoic acid), 0.1 ; glycine pH 7.5, 300; enzyme preparation, 10 to $100 \mu 1$; final volume, I $\mathrm{ml}$. The assay mixture, without glycine, was used to correct for any glycine-independent deacylase activity; specific activities were calculated as nmol CoASH released as sulphydryl groups $\mathrm{min}^{-1}$ (mg protein) ${ }^{-1}$.

Release of $\mathrm{CO}_{2}$. The release of carbon dioxide from $\mathrm{L}-\left[\mathrm{U}-{ }^{14} \mathrm{C}\right]$ threonine by broken cell preparations was determined in conical flasks, sealed with a serum cap, with a centre well containing Hyamine hydroxide and a small piece of filter paper to aid absorption. The incubation medium contained (mM): Tris/ $\mathrm{HCl} \mathrm{pH} \mathrm{8.5,} \mathrm{200;}$ L-threonine, 3 (I $\mu \mathrm{Ci}$ ); $\mathrm{KHCO}_{3}, 5$ (to prevent recycling of $\mathrm{CO}_{2}$ ); NAD ${ }^{+}, 3$; and $\mathrm{MnSO}_{4}, 50 \mu \mathrm{M}$ (to catalyse the breakdown of 2-amino-3-oxobutyric acid). The reaction was stopped with perchloric acid. Threonine dehydrogenase activity and radioactive $\mathrm{CO}_{2}$ were determined under identical conditions with the same enzyme preparation.

Estimations. Protein concentrations were determined by the method by Lowry et al. (195I), using bovine serum albumin as a standard. A correction was applied for the interference by buffer components in the assay.

The radioactivity of aqueous solutions was determined with a liquid scintillation spectrometer using a water-compatible scintillation fluid containing methanol/Triton $X-100 /$ toluene $(1: 6: 13$, by vol.) and $5 \mathrm{~g}$ 2,5-diphenyloxazole $1^{-1}$, together with $0.5 \mathrm{~g}$ 1,4-di-2(5-phenyloxazolyl)benzene $1^{-1}$. Counting efficiency was determined using an external standard.

Column separation. Gel filtration of a soluble extract of $T$. b. brucei $\mathrm{S} 42$ (bloodstream form) was carried out on a $70 \times 1.6 \mathrm{~cm}$ column of Sephadex G-200 at $4{ }^{\circ} \mathrm{C}$. A sample containing $10.6 \mathrm{mg}$ protein, dissolved in $1.5 \mathrm{ml} 50 \mathrm{~mm}$-Tris/HCl (pH 8.0, $20^{\circ} \mathrm{C}$ ) containing $0.5 \mathrm{mM}-\mathrm{NAD}^{+}$and I mM-dithiothreitol, was applied to the column and eluted with this buffer. Fractions were collected and assayed for threonine dehydrogenase activity and protein content. The column was calibrated for the determination of molecular weight using bovine serum albumin, ovalbumin, lysozyme, and cytochrome $c$ as standards. The void volume was obtained using blue dextran (BD 2000, Pharmacia). The molecular weight of threonine dehydrogenase was estimated from a plot of relative retention volume $\left(K_{\mathrm{av}}\right)$ against $\log _{10}$ (molecular weight) (Andrews, I964, 1965).

Gel electrophoresis. This was carried out in polyacrylamide gels $(5.6 \%, \mathrm{w} / \mathrm{v})$ using $0.37 \mathrm{M}$-Tris/glycine buffer pH 8.3 at $10^{\circ} \mathrm{C}$. After electrophoresis ( $2 \mathrm{~mA} \mathrm{gel}{ }^{-1}, 4$ to $6 \mathrm{~h}$ ) the gels were stained for protein with Coomassie blue, or for threonine dehydrogenase activity by incubating the gels for $\mathrm{I} h$ in the dark at room temperature in the following solution (mM): L-threonine, 30 ; Tris/HCl pH 8.5, I00; $\mathrm{NAD}^{+}, \mathrm{I} \cdot 5$; phenazine methosulphate, 0.082 ; and nitro blue tetrazolium, 0.31 . The gel was calibrated with phosphorylase, bovine serum albumin, glyceraldehyde-3-phosphate dehydrogenase, carbonic anhydrase and lysozyme; all markers were of analytical grade purity. The apparent molecular weight of the threonine dehydrogenase was estimated by plotting $\log _{10}$ (molecular weight) against migration, relative to the bromophenol blue marker. No substrate-independent reduction of $\mathrm{NAD}^{+}$was detected.

Amino-acid analysis. This was done using a Locarte automatic amino-acid analyser coupled to a Panax flow-type scintillation detector as described by Cross et al. (1975). 


\section{RESULTS}

\section{Identification of aminoacetone produced by cell extracts}

Intact culture-form $T . b$. bruce $\mathrm{S} 42$ produce equimolar amounts of radiolabelled acetate and glycine when incubated in the presence of $\mathrm{L}_{-}\left[\mathrm{U}_{-}{ }^{14} \mathrm{C}\right]$ threonine (Cross et al., 1975). These experiments gave no indication of the enzymic steps involved; however, when extracts of culture-form $T . b$. brucei $\mathbf{s} 42$, prepared by either Triton X-100 lysis or sonication, were incubated in the presence of $\mathrm{L}-\left[\mathrm{U}-{ }^{14} \mathrm{C}\right]$ threonine, the formation of acetate and glycine was much reduced. Moreover, a radioactive peak appeared after separation of the reaction products using an automatic amino-acid analyser, corresponding to a more basic compound which was not present in incubation mixtures containing whole cells (Fig. 1). The formation of the new peak X, which eluted after 135 min near to the position of the ammonia peak, was stimulated by the presence of $\mathrm{NAD}^{+}$, but not by NADP+. The addition of CoASH together with $\mathrm{NAD}^{+}$stimulated the formation of glycine and acetate, as well as the unidentified peak. Addition of pyridoxal 5-phosphate inhibited the formation of the unidentified peak, and also gave rise to a number of more acidic peaks.

It seemed most likely that the basic compound X might be I-aminopropan-2-one (aminoacetone), produced through the activity of a $\mathrm{NAD}^{+}$-dependent threonine dehydrogenase followed by spontaneous decarboxylation of the notoriously unstable intermediate 2-amino-3-oxobutyric acid (Laver, Neuberger \& Scott, 1959). The unknown compound X co-chromatographed with authentic aminoacetone when run on an amino-acid analyser, appearing at the leading edge of the ammonia peak. In order to achieve a more rigorous proof of identity, compound $\mathrm{X}$ was purified by collecting the radioactive peak as it was eluted from the column of the amino-acid analyser; unlabelled authentic aminoacetone hydrochloride was added to the radioactive material, and the crystalline semicarbazone derivative was prepared. The product was recrystallized five times and the specific activity of the material was determined at every stage after the second recrystallization (Table I). All of the radioactivity associated with the basic peak could be accounted for in terms of the final specific activity of the derivative and the amount of carrier aminoacetone added (recovery ro $\pm 4 \%$ S.D., $n=6$ ). This provides conclusive evidence that the unknown substance is indeed aminoacetone.

Results similar to those above were obtained for bloodstream forms of $T$. brucei 427 , although the overall activity of the pathway was considerably less, as judged by the appearance of glycine, acetate and aminoacetone.

\section{Presence of $\mathrm{L}$-threonine dehydrogenase and aminoacetone synthase}

Threonine dehydrogenase and aminoacetone synthase were assayed in homogenates prepared from bloodstream and culture forms of $T$. brucei. The threonine dehydrogenase levels in bloodstream forms of $T . b$. brucei $\mathrm{s}_{2} 2$ and $T$. brucei 427 were not significantly dif-

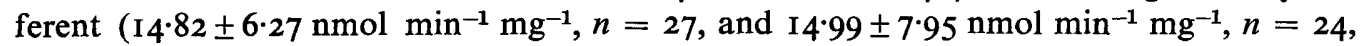
respectively). There was, however, a highly significant difference ( $t$ test, $P \ll 0.00 \mathrm{I})$ between the levels in the culture (II7. I $\left.\pm 46.6 \mathrm{nmol} \mathrm{min}^{-1} \mathrm{mg}^{-1}, n=2 \mathrm{I}\right)$ and bloodstream forms of strain S42. The difference between the aminoacetone synthase activities for the bloodstream form of strain 427 and the culture form of strain $\$ 42$ was probably not significant (0.10 $>P>0.05)$ in view of the small number of determinations $(5.3 \mathrm{I} \pm 0.53 \mathrm{nmol}$

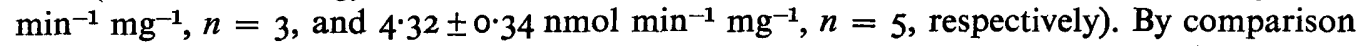
Crithidia fasciculata, which possesses appreciable pyruvate dehydrogenase activity (D. J. Linstead, P. G. G. Miller and R. A. Klein, unpublished observations), showed only a low level of threonine dehydrogenase activity $\left(0.50 \pm 0.22 \mathrm{nmol} \mathrm{min} \mathrm{mg}^{-1} \mathrm{mg}^{-1}, n=10\right)$.

The operation of a catabolic pathway for L-threonine involving the highly unstable intermediate, 2-amino-3-oxobutyric acid, implies that the threonine dehydrogenase and amino- 


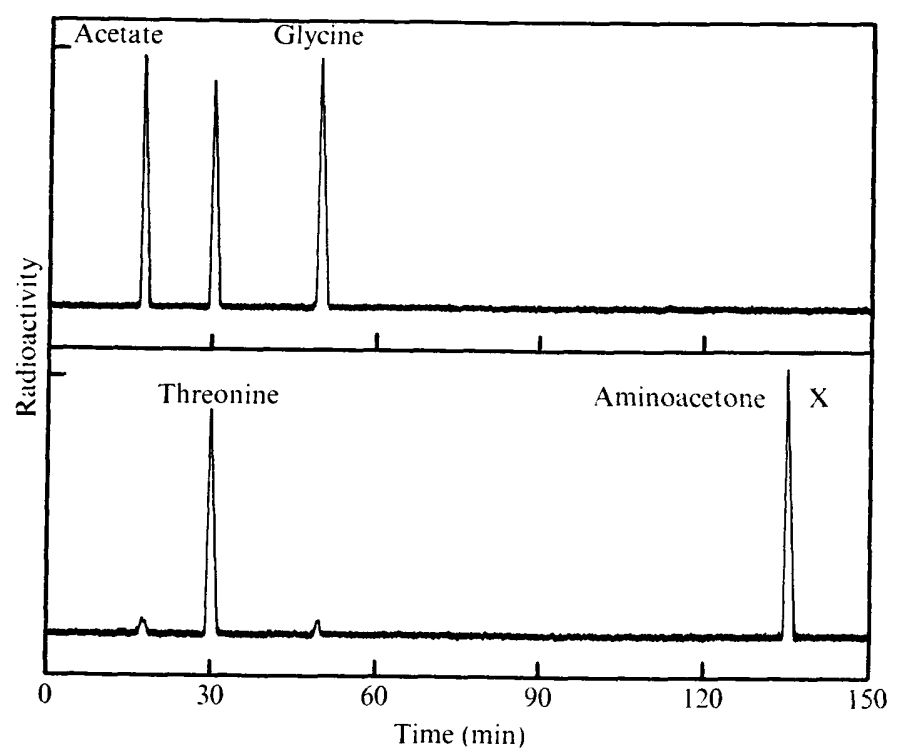

Fig. I. Chromatographic separation, using a Locarte automatic amino-acid analyser, of the products of radioactively-labelled L-threonine breakdown by culture-form Trypanosoma brucei brucei s42. The upper trace was obtained with whole cells, and the lower trace after the cells had been lysed with $0.01 \%$ Triton X-100.

Table I. Specific activity of aminoacetone semicarbazone hydrochloride after successive recrystallizations from ethanol/water $(5: 2, v / v)$

The derivative was prepared from an excess of unlabelled aminoacetone hydrochloride in the presence of the radioactively-labelled unknown compound. Specific activity values are given as the mean of six measurements.

Recrystallization
step
Second
Third
Fourth
Fifth

$\begin{gathered}\text { Specific activity } \\ \text { (d.p.m. } \mu \mathrm{g}^{-1} \text { ) }\end{gathered}$
$6.10 \pm 0.05$
$6.49 \pm 0.17$
$6.77 \pm 0.14$
$6.65 \pm 0.12$

acetone synthase are tightly coupled both physically and functionally in whole cells. The production of aminoacetone in broken cell preparations suggests that under these conditions (i.e. detergent lysis or sonication) this coupling is destroyed. One would predict that for each molecule of L-threonine oxidized via this pathway in broken cell preparations, one molecule of carbon dioxide should be released as a result of the spontaneous decarboxylation of 2-amino-3-oxobutyric acid. In whole cell preparations very little carbon dioxide is released as a product of threonine breakdown (threonine dehydrogenase activity, 52 to

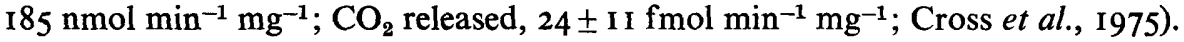

Bloodstream forms were used to test this prediction because larger amounts of material were readily available. Two separate experiments were carried out which showed that a quarter $(0.233 \pm 0.044$ and $0.258 \pm 0.027)$ of the threonine carbon atoms were released as $\mathrm{CO}_{2}$ with a broken cell preparation: this is equivalent to one molecule (0.932 and $\left.\mathrm{I} \cdot 032\right)$ of carbon dioxide being produced from each molecule of L-threonine, thus supporting the hypothesis. Control experiments gave values for ${ }^{14} \mathrm{CO}_{2}$ release which were $<5 \%$ of those for the broken cell preparations; these could be satisfactorily explained on the basis of a small percentage of lysed cells arising from the preparative procedures. No $\mathrm{NAD}^{+-}$or $\mathrm{NADP}^{+}$ 


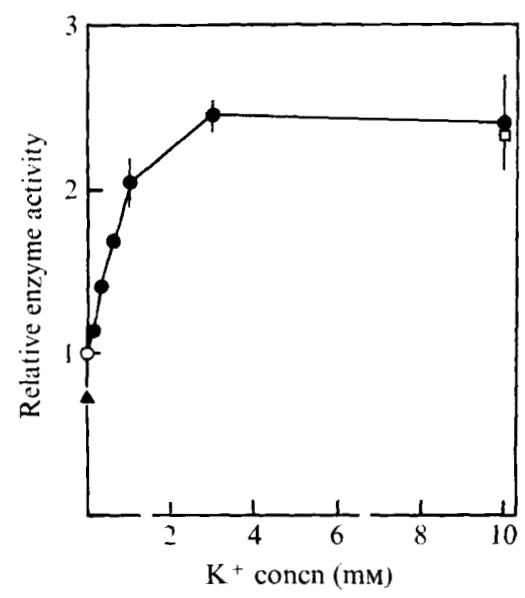

Fig. 2

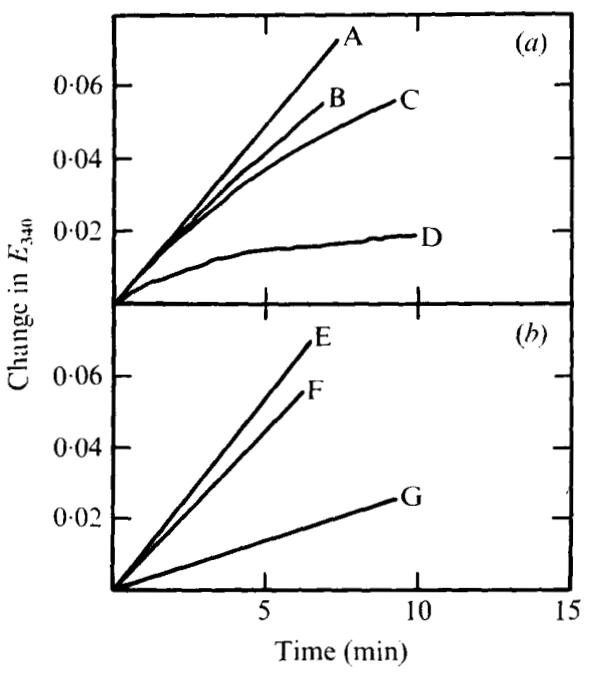

Fig. 3

Fig. 2. Activation of L-threonine dehydrogenase from the bloodstream form of Trypanosoma brucei 427 by potassium ions. Potassium ions were added to the reaction cuvette in the form of $\mathrm{KHCO}_{3}$ at the concentrations shown, and the threonine dehydrogenase activity was followed spectrophotometrically (O). Controls of $10 \mathrm{~mm}-\mathrm{KCl}(\square)$ and $10 \mathrm{~mm}-\mathrm{NaHCO}_{3}(\Delta)$ are shown. The enzyme activity in the absence of added $\mathrm{K}^{+}$or $\mathrm{Na}^{+}$ions is also shown $(\mathrm{O})=\mathbf{I} \cdot 00$.

Fig. 3. (a) Effect of tetraethyl thiuram disulphide (TETD) on L-threonine dehydrogenase from culture-form Trypanosoma brucei brucei s42. The concentrations $\left(\mu \mathrm{g} \mathrm{ml}^{-1}\right)$ of TETD, added as a solution in ethanol, were: (A) o, (B) I, (C) 2.5 and (D) 10 . (b) Effect of reduced glutathione (GSH) on the ability of TETD to inhibit L-threonine dehydrogenase from culture-form $T . b$. brucei $\$ 42$. (E) Control rate, no additions; (F) 1 mM-GSH added followed by $10 \mu \mathrm{g}^{\text {TETD }} \mathrm{ml}^{-1}$; (G) preincubated for $3 \mathrm{~min}$ with $10 \mu \mathrm{g}$ TETD $\mathrm{ml}^{-1}$, and then I mM-GSH was added.

dependent I-aminopropan-2-ol dehydrogenase activity could be demonstrated. NADH oxidase activity was less than $0.5 \%$ of the threonine dehydrogenase activity.

The activity of the threonine dehydrogenase in crude extracts showed a broad $\mathrm{pH}$ optimum between $\mathrm{pH} 8.5$ and 9.5 . This optimum corresponds closely with that for the production of glycine and acetate by culture forms, and aminoacetone by broken cell preparations. Enzyme activity was not affected by the use of Tris $/ \mathrm{HCl}$, phosphate or diethyl barbiturate buffers; borate was inhibitory at high $\mathrm{pH}(8 \cdot 5)$.

\section{Properties of $\mathrm{L}$-threonine dehydrogenase in crude homogenates}

The dehydrogenase was specific for L-threonine. No activity was observed with D-threonine, nor was this enantiomer an inhibitor as judged by the reaction rate with DL-threonine. The specificity of the enzyme for $\mathrm{NAD}^{+}$, as opposed to NADP ${ }^{+}$, was stringent at equimolar concentrations, in agreement with the requirement for $\mathrm{NAD}^{+}$for aminoacetone production. L-Threonine dehydrogenase activity was not inhibited by 5 mM-EDTA. It appears unlikely, therefore, that the enzyme contains bound divalent cations essential for its activity. In this respect it differs from the enzyme obtained from Arthrobacter sp. (McGilvray \& Morris, 1969) and Rhodopseudomonas spheroides (Neuberger \& Tait, I962), but is similar to preparations from bull frog mitochondria (Hartshorne \& Greenberg, 1964), Escherichia coli (Turner, 1967) and Staphylococcus aureus (Green \& Elliott, 1964; Green, 1964).

The enzyme from the bloodstream form of $T$. brucei 427 was activated by potassium ions as shown in Fig. 2; sodium ions were slightly inhibitory. Half-maximal stimulation occurred at a potassium concentration of approximately $0.5 \mathrm{mM}$. Potassium ions brought about an increase in the $V_{\max }$ value, rather than a change in the $K_{\mathrm{m}}$ value for L-threonine. The $K_{\mathrm{m}}$ 
value in the absence of potassium was $15.3 \mathrm{mM}$, compared with $14.3 \mathrm{~mm}$ in the presence of 5 mM-potassium bicarbonate. An apparent $K_{\mathrm{m}}$ value of 0.20 to $0.25 \mathrm{~mm}$ was obtained for $\mathrm{NAD}^{+}$in the presence of $30 \mathrm{mM}-\mathrm{L}-\mathrm{threonine}$. These values are similar to those reported for various bacterial enzymes (Bell \& Turner, 1976).

The breakdown of L-threonine to yield glycine and acetate is strongly inhibited by tetraethyl thiuram disulphide (TETD) (Cross et al., 1975). Threonine dehydrogenase was also markedly inhibited by TETD with an ID $_{50}$ of $5.2 \mu \mathrm{M}$; aminoacetone synthase, on the other hand, was not affected by concentrations of TETD as high as $150 \mu \mathrm{M}$. The inhibition of threonine dehydrogenase by TETD was concentration-dependent and progressive, increasing with time (see Fig. $3 a$ ). The progressive nature of the inhibition suggested an irreversible mechanism; the possibility that this involved thiocarbamoylation of an essential sulphydryl group was tested by pre-incubation of the enzyme with reduced glutathione (GSH). This greatly reduced the inhibitory effect of TETD; if, however, GSH was added after the TETD, the protective effect was greatly reduced and the inhibition already present was not reversed. GSH prevented the progressive inhibition shown by TETD alone (Fig. $3 b$ ); moreover, this occurred whether the GSH was added before the TETD (F), or after $(\mathrm{G})$, and resulted in a linear time course. The threonine dehydrogenase from either bloodstream or culture forms of $T . b$. brucei $\mathrm{s} 42$ showed no apparent difference in its sensitivity to inhibition by TETD.

Four other disulphide compounds inhibited the threonine dehydrogenase. These were tetramethyl thiuram disulphide ( $\left.\operatorname{ID}_{50} 4.5 \mu \mathrm{M}\right), 5,5^{\prime}$-dithiobis(2-nitrobenzoic acid) $\left(\mathrm{ID}_{50} \mathrm{I} 5.8 \mu \mathrm{M}\right)$, 2-aminophenyl disulphide (ID $\left.{ }_{50}^{\prime} 25 \mu \mathrm{M}\right)$, and 6-dithionicotinic acid (ID ${ }_{50} 60 \mu \mathrm{M}$ ); 4 -aminophenyl disulphide was inactive. Threonine dehydrogenase activity was completely inhibited by the sulphydryl reagents $N$-ethylmaleimide (I.5 mM), p-chloromercuribenzoic acid $(75 \mu \mathrm{M})$ and $p$-chloromercuribenzenesulphonic acid $(75 \mu \mathrm{M})$. Inhibition with iodoacetamide was only achieved using high concentrations $(30 \mathrm{~mm})$ and prolonged reaction times $\left(60 \mathrm{~min}, 0^{\circ} \mathrm{C}\right)$. Iodoacetic acid was inactive under similar conditions suggesting perhaps that the essential sulphydryl group is hidden in an hydrophobic pocket. Enzyme activity was completely inhibited by $50 \mu \mathrm{M}-\mathrm{Ag}^{2+}, \mathrm{Hg}^{2+}$ and $\mathrm{Cu}^{2+}$ ions; $50 \mu \mathrm{M}-\mathrm{Co}^{2+}$ was not inhibitory.

Polyacrylamide gel electrophoresis and specific staining for threonine dehydrogenase gave apparent molecular weights of 27900 to 32400 (bloodstream form) and 33000 to 38000 (culture form). Although these gels had to be run in the absence of sodium dodecyl sulphate, the values obtained are similar to that obtained for the enzyme from bloodstream forms ( 32000 to 33000) on a column of Sephadex G-200. The enzyme is soluble, with the majority of the activity appearing in the $30000 \mathrm{~g}_{\mathrm{av}}$ supernatant for preparations from bloodstream and cultured trypanosomes.

\section{DISCUSSION}

Both the bloodstream and culture forms of Trypanosoma brucei degrade L-threonine to acetate and glycine by a pathway which requires $\mathrm{NAD}^{+}$and coenzyme $\mathrm{A}$; L-threonine dehydrogenase and aminoacetone synthase (acetyl-CoA:glycine $C$-acetyltransferase) have been identified as the key enzymes in both forms of the organism. The flux through this catabolic pathway is greater in the culture form, and is associated with a very much higher $(\times 7$ to 8 ) level of threonine dehydrogenase activity.

L-Threonine breakdown proceeds via 2-amino-3-oxobutyric acid which, in cell homogenates, spontaneously decarboxylates to yield aminoacetone. 2-Amino-3-oxobutyric acid is unstable in aqueous solutions, and particularly so at alkaline $\mathrm{pH}$, with a half-life of less than $\mathrm{I}$ min at room temperature and $\mathrm{pH} 7$ (Laver et al., 1959). Consequently the two enzymes of the pathway must be closely coupled in vivo, both physically and functionally. A similar result has been reported recently for a number of bacterial species (Bell \& Turner, 1976); these authors also showed that the dehydrogenase and the transferase were induced together when the growth substrate was L-threonine. 
The acetyl-CoA generated by this pathway is presumably deacylated to yield acetate. We have shown recently that a number of trypanosomatid flagellates, including $T$. b. brucei S42 and $T$. brucei 427 , possess a highly active, carnitine-sensitive, acetyl-CoA deacylase system (Klein, Miller \& Linstead, 1976); moreover, both bloodstream and culture forms of T. b. brucei $\mathrm{S} 42$ possess deacylase activity (R. A. Klein and D. J. Linstead, unpublished observations). The significance of acetyl-CoA hydrolysis under conditions of high threonine breakdown may be to relieve acetyl pressure on the cellular CoA pool, as suggested by Pearson \& Tubbs (1967) and Costa \& Snoswell (1975), since neither T. b. brucei S42 nor T. brucei 427 appears to possess a functional tricarboxylic acid cycle with the ability to oxidize acetyl-CoA.

In culture-form $T . b$. bruce $\mathrm{s} 42$, the acetyl-CoA derived from threonine is a preferred source of lipid carbon even in the presence of large amounts of exogenous acetate and glucose (Klein \& Cross, 1975; Klein \& Linstead, 1976). It is likely that the threonine pathway acts as an alternative source of acetyl-CoA, particularly in those organisms with low levels of pyruvate dehydrogenase. The ratio of threonine dehydrogenase to pyruvate dehydrogenase activity may show considerable variation from organism to organism; for example, the ratio for both $T . b$. brucei $\mathrm{S} 42$ and $T$. brucei 427 is approximately 16 , for a number of Schizotrypanum species I or less, and for Crithidia fasciculata 0.07 (D. J. Linstead, P. G. G. Miller and R. A. Klein, unpublished observations).

The sensitivity of the dehydrogenase to TETD was of particular interest, since this drug is rapidly trypanocidal in culture at very low concentrations (Cross et al., 1975). Various liver aldehyde dehydrogenases have comparable sensitivity to inhibition by TETD and other disulphides, with an interesting differential sensitivity being apparent for the cytoplasmic and mitochondrial enzymes in sheep liver (Graham, 195I; Kitson, 1975, 1976). The extremely steep dose-response curve exhibited by trypanosomes in culture is probably related to the time-dependent irreversible inhibition of the threonine dehydrogenase; a similar phenomenon for sheep liver aldehyde dehydrogenase has been described by Kitson (1975). We would suggest that the effectiveness of TETD as a trypanocide under culture conditions, reflects the preferred utilization for lipid synthesis of acetyl-CoA generated from threonine (Klein \& Linstead, 1976). TETD shows almost no activity against trypanosomes in vivo, presumably due to inactivation by the readily available protein sulphydryl groups in the tissues and body fluids.

We should like to express our thanks to David Taylor for his cooperation in obtaining material used in this work.

\section{REFERENCES}

ANDREWS, P. (1964). Estimation of the molecular weights of proteins by Sephadex gel-filtration. Biochemical Journal 9r, 222-233.

ANDREWS, P. (1965). The gel-filtration behaviour of proteins related to their molecular weights over a wide range. Biochemical Journal 96, 595-606.

Bell, S. C. \& Turner, J. M. (1976). Bacterial catabolism of threonine. Biochemical Journal I56, 449-458.

Costa, N. D. \& Snoswell, A. M. (1975). Enzymic hydrolysis of acetylcarnitine in liver from rats, sheep and cows. Biochemical Journal 152, 16II66.

Cross, G. A. M. \& Manning, J. C. (1973). Cultivation of Trypanosoma brucei sspp. in semidefined media. Parasitology 67, 31 5-331.

Cross, G. A. M., Klein, R. A. \& Linstead, D. J. (1975). Utilization of amino acids by Trypanosoma brucei in culture: $\mathbf{L}$-threonine as a precursor for acetate. Parasitology 71, 31 1 -326.

Cummings, A. D. \& Simmons, H. E. (1928). Some observations with ultra-accelerators. Industrial and Engineering Chemistry 20, I $173-1176$.

EllmaN, G. L. (1959). Tissue sulfhydryl groups. Archives of Biochemistry and Biophysics 82, 70-77.

GaItonde, M. K. (1975). Conversion of [U_-14C]threonine into ${ }^{14} \mathrm{C}$-labelled amino acids in the brain of thiamin-deficient rats. Biochemical Journal 150, 285-295.

GraHAM, W. D. (I95I). In vitro inhibition of liver aldehyde dehydrogenase by tetraethylthiuram disulphide. Journal of Pharmacy and Pharmacology 3, 160-I 68 .

GreEN, M. L. (1964). The activation of L-threonine dehydrogenase by potassium ions. Biochemical Journal 92, 550-555. 
Green, M. L. \& ElliotT, W. H. (1964). The enzymic formation of aminoacetone from threonine and its further metabolism. Biochemical Journal 92, 537-549.

Hartshorne, D. \& Greenberg, D. M. (1964). Studies on liver threonine dehydrogenase. $\mathrm{Ar}$ chives of Biochemistry and Biophysics ro5, 173178.

Hepworth, J. D. (1973). Aminoacetone semicarbazone hydrochloride. Organic Syntheses: Collected Volume 5, 27-29.

KaraseK, M. A. \& GreenberG, D. M. (1957). Studies on the properties of threonine aldolases. Journal of Biological Chemistry 227, 191-205.

Kidder, G. W. \& DutTA, B. N. (I958). The growth and nutrition of Crithidia fasciculata. Journal of General Microbiology 18, 62 I-638.

Kitson, T. M. (1975). The effect of disulfiram on the aldehyde dehydrogenase of sheep liver. Biochemical Journal r51, 407-4I 2.

KrTson, T. M. (1976). The effect of some analogues of disulfiram on the aldehyde dehydrogenase of sheep liver. Biochemical Journal I55, 445-448.

KleIN, R. A. \& Cross, G. A. M. (I975). Threonine as a two-carbon precursor for lipid synthesis in Trypanosoma brucei. Transactions of the Royal Society of Tropical Medicine and Hygiene 69, 267.

Klein, R. A. \& Linstead, D. J. (1976). Threonine as a preferred source of 2-carbon units for lipid synthesis in Trypanosoma brucei. Biochemical Society Transactions 4, 48-50.

Klein, R. A., Linstead, D. J. \& WheEler, M. V. (1975). Carbon dioxide fixation in trypanosomatids. Parasitology 71, 93-107.

Klein, R. A., Miller, P. G. G. \& Linstead, D. J. (I976). The enzymic hydrolysis of acetyl-coenzyme A by trypanosomatid flagellates. Biochemical Society Transactions 4, 285-287.

LANHAM, S. M. (I968). Separation of trypanosomes from the blood of infected rats and mice by anionexchangers. Nature, London 218, 1273-1 274.
LAVer, W. G., Neuberger, A. \& Scott, J. J. (I959). $\alpha$-Amino- $\beta$-keto-acids. II. Rates of decarboxylation of the free acids and the behaviour of derivatives on titration. Journal of the Chemical Society, I483-I49I.

Lowry, O. H., RoSebrough, N. J., FARr, A. L. \& Randall, R. J. (195I). Protein measurement with the Folin phenol reagent. Journal of Biological Chemistry 193, 265-275.

MCGILVRAY, D. \& MORRIS, J. G. (1969). Utilization of L-threonine by a species of Arthrobacter. A novel catabolic role for 'aminoacetone synthase'. Biochemical Journal r12, 657-67I.

MCGILVRAY, D. \& MORRIS, J. G. (I97I $a$ ). Lthreonine dehydrogenase (Arthrobacter). Methods in Enzymology $17 \mathrm{~B}, 580-584$.

MCGilvray, D. \& Morris, J. G. (I97I $b$ ). Aminoacetone synthase (Arthrobacter). Methods in Enzymology r7B, 585-589.

MoRRIs, J. G. (1969). Utilization of L-threonine by a pseudomonad: a catabolic role for L-threonine aldolase. Biochemical Journal Ir5, 603-605.

Neuberger, A. \& Tait, G. H. (I962). Production of aminoacetone by Rhodopseudomonas spheroides. Biochemical Journal 84, 317-328.

Pearson, D. J. \& Tubbs, P. K. (1967). Carnitine and derivatives in rat tissue. Biochemical Journal I05, 953-963.

TURNER, J. M. (1967). Microbial metabolism of amino ketones. L-I-Aminopropan-2-ol dehydrogenase and L-threonine dehydrogenase in Escherichia coli. Biochemical Journal 104, I $12-121$.

UMBARGER, H. E. \& BRown, B. (1957). Threonine deamination in Escherichia coli. II. Evidence for two L-threonine deaminases. Journal of Bacteriology 73, 105-I I 2.

VoGel, A. I. (1959). A Textbook of Practical Organic Chemistry, 3rd edn. London: Longmans. 